\title{
A comparative study of bonded and non-bonded amalgam restorations in general dental practice
}

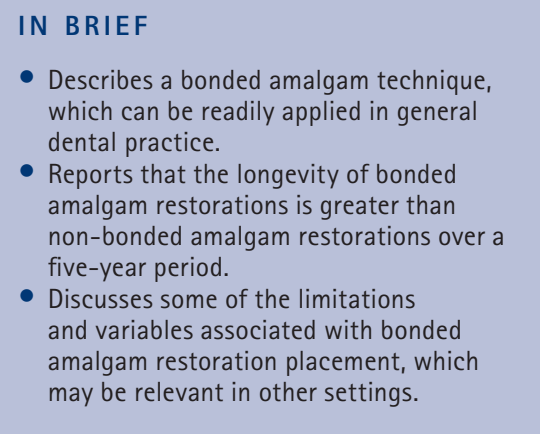

\section{VERIFIABLE CPD PAPER}

\begin{abstract}
Objective This study compared the performance of non-bonded and bonded amalgam restorations in a general dental practice. Materials and methods A retrospective cohort study was carried out in a general dental practice of amalgam restorations, placed by a single operator. Non-bonded amalgam restorations were analysed over a ten-year period and bonded amalgam restorations over a five-year period. Survival analysis using the Kaplan-Maier method was carried out and an analysis of postoperative sensitivity and reasons for failure. Results Each group consisted of 231 restorations in 135 patients. Survival rates of non-bonded amalgam restorations were $72.2 \%$ over five years and $51.0 \%$ over ten years. The survival rate for bonded amalgam restorations was $85.0 \%$ over five years. The difference was significant ( $p<0.0001$, $95 \% \mathrm{Cl} 1.510-3.226$ ). Analysis of postoperative sensitivity and reasons for failure were inconclusive. Conclusion Within the limitations of the study, bonded amalgam restorations demonstrated greater longevity over non-bonded amalgam restorations and offer significant benefit to patients. Clinicians may feel confident to offer bonded amalgam restorations for their patients as a better alternative than non-bonded amalgam restorations.
\end{abstract}

\section{INTRODUCTION}

Amalgam has been used to restore teeth since before G. V. Black described the classification of cavities over 100 years ago and is still a first choice material used by most clinicians to restore carious teeth, where aesthetics is not an overriding concern. ${ }^{1}$ For much of this time the main ingredients of amalgam have been used in a conventional form. ${ }^{2}$ Conventional amalgam alloy contains a minimum of $60 \%$ silver, a maximum of $29 \%$ tin, less than $6 \%$ copper with a trace amount of zinc. Its chemical composition contains the $\gamma 2$ phase, which is most prone to corrosion and the release of mercury vapour. ${ }^{3}$ The alloy was also produced in lathe-cut form, in which the shape of the alloy particles was irregular and angular.

Principal changes to amalgam have been to the alloy composition. In 1962 spherical particle alloys were introduced. This

'Amblecote Dental Care, 181 Amblecote Road, Brierley Hill, West Midlands, DY5 2PR

*Correspondence to: Dr Paul Worskett

Email:paul@amblecotedental.co.uk

Online article number E19

Refereed Paper - accepted 20 December 2012

DOI: 10.1038/sj.bdj.2013.328

${ }^{\ominus}$ British Dental Journal 2013; 214: E19 improved the handling characteristics and setting time. However, they require thorough condensation during placement to ensure good marginal adaptation. ${ }^{1}$ High copper content alloys were introduced the following year and the effect of the increased copper (13-20\%) resulted in the elimination of the $\gamma 2$ phase of the alloy and, in turn, this reduced corrosion and mercury release. ${ }^{3}$ Additional benefits of high-copper alloys include improved compression strength, faster setting time and durable performance with the retention of a smooth, non-pitted surface for many years. ${ }^{1,4,5}$

Cavity design has also changed in tandem with improvements to the materials, evidence-based practice and developing technology. The concept of extension for prevention has been superseded by a philosophy of 'prevention of extension'6 and minimally invasive dentistry is at the heart of a modern approach to caries management. ${ }^{7,8}$ Cavity design has therefore become more conservative, with preservation of precious tooth tissue; although when no means of chemically bonding amalgam to the tooth surface is used, mechanical retention is still necessary to prevent the amalgam restorations from becoming dislodged.
A relatively recent development in the progress of amalgam restorations has been the introduction of bonded amalgam restorations. Setcos, Staninec and Wilson ${ }^{9}$ postulated that the theoretical advantages of bonding amalgam restorations are that:

- Bonding creates an adhesion between amalgam and the tooth surface, which means that reliance on macromechanical retention is reduced or eliminated, allowing cavity preparation to be more conservative without the need for pins

- Bonding improves inherent tooth strength and fracture resistance

- Bonding creates a better marginal seal, reducing the risk of dentine and pulpal contamination and reduced incidence of secondary caries

- Bonding reduces postoperative sensitivity.

Buonocore laid the foundations for adhesive dentistry in 1955 with the concept of acid etching of enamel. ${ }^{10}$ Fusayama took this one stage further by bonding to dentine ${ }^{11}$ and Nakabayashi explained the hybrid layer. ${ }^{12}$ Since then improvements have been made to various 'generations' of dental adhesives to overcome 
various shortcomings and to improve bond strengths. ${ }^{9}$ The strength of a compositeenamel bond of between 20-25 MPa is thought to be sufficient to overcome polymerisation shrinkage and temperature related changes; however, it may be considered that requirements for amalgam may be less than this since amalgam, once set, is more dimensionally stable. ${ }^{13}$

\section{Laboratory studies}

Following early developments in the mid-1980s with metal-adhesive resin cements, ${ }^{14,15}$ a number of in-vitro studies carried out in the 1990s reported the advantages of bonded amalgams, with Panavia $^{\mathrm{TM}}$, a bis-GMA phosphonated ester (Panavia-Ex, Kuraray, Osaka, Japan) leading the way; the MDP monomer component chemically bonding to hydroxyapatite. Other systems employed a 4-META/MMA resin base with HEMA as the adhesive agent (for example, Amalgambond ${ }^{\mathrm{TM}}$, Parkell, NY, USA); and filled resin combinations, such as Amalgambond Plus ${ }^{\mathrm{TM}}$ (Parkell, NY, USA), which included PMMA as a filler, and ONE-STEP $^{\text {TM}} /$ Resinomer $^{\mathrm{TM}}$ (BISCO, IL, USA). Staninec and Holt found that amalgam bonded with Panavia demonstrated bond strengths of approximately $10 \mathrm{MPa}$ and $3 \mathrm{MPa}$ to enamel and dentine respectively, ${ }^{16}$ while other workers have demonstrated bond strengths of up to $15 \mathrm{MPa}$ with various adhesive/amalgam combinations. ${ }^{17,18}$ In another study, Staninec found that bonding resulted in greater resistance to displacement than either dovetails or grooves. ${ }^{19}$ It has been shown that preparing teeth for restoration results in weakening and susceptibility to fracture. ${ }^{20}$ Many studies have reported that teeth restored with bonded amalgams were more resistant to fracture than non-bonded amalgams, may result in less risk of cusp fracture and that the integral strength of teeth restored with bonded amalgam restorations increased the strength of the teeth, especially MOD restorations. ${ }^{21-25}$

Branstromm considered that the greatest threat to dental pulps while restoring teeth is infection, which can cause postoperative sensitivity, pulpitis and secondary caries. ${ }^{26}$ He advocated removing the smear layer (which contains microorganisms), disinfecting the walls of the cavity and sealing the preparation to prevent any ingress of further contaminants. Cox et al. also demonstrated that, provided a restoration is effectively sealed and bacteria excluded, restorative materials are well tolerated by the pulp. ${ }^{27}$ Prevention of microleakage is, therefore, critical to the long-term success of restorations. Laboratory studies have concluded that bonded amalgam restorations result in reduced marginal leakage compared to conventionally filled amalgam restorations. ${ }^{16,28-30}$ Furthermore, leakage tends to occur at the resin-amalgam interface, rather than the resin-tooth interface. ${ }^{31}$

As more bonding products were developed and used in conjunction with different alloys it became apparent that varying adhesive/alloy combinations resulted in different bond strengths, although choice of amalgam was less important than choice of adhesive, and the highest strengths were obtained with filled resin cements, with Panavia EX achieving over $20 \mathrm{MPa}$ shear bond strength. ${ }^{18,32}$

Although laboratory studies are a useful setting for testing out new materials, the only means of testing the performance of a material or technique clinically is in studies carried out in vivo.

\section{Clinical studies}

A Cochrane review published in 2009 could find only one randomised controlled trial on the comparison of bonded versus non-bonded amalgam restorations. ${ }^{33}$ The trial referred to, carried out in a university setting by researchers, consisted of a small sample size (31 patients), with 113 restorations and the follow up period was for only two years. ${ }^{34}$ They concluded that there was no significant difference in survival between the two methods. While the methodology of the trial may have been sound, the setting, sample size and duration question the relevance of the findings in relation to general dental practice.

Other clinical studies have also concluded that there was no significant difference in survival between bonded and non-bonded restorations. ${ }^{4,35-38}$ However, studies have also found that cavity preparations could be more conservatively designed and retention pins were unnecessary where a bonded technique is used..$^{39,40}$

Microleakage is detectable clinically by symptoms of pulpal irritation or secondary caries in the long term, or sensitivity in the short term. ${ }^{41}$ There is no evidence of any difference in sensitivity between bonded and non-bonded amalgams restorations.
In all of the clinical studies found in the literature, none of the studies used subjects with high caries rates and the incidence of caries was generally low. Consequently, it has not been possible to demonstrate that the inhibition of caries by bonded amalgam restorations is greater than nonbonded amalgam restorations.

\section{Aim and objectives of the study}

Although there is a plethora of laboratory studies, which demonstrate the theoretical advantages of bonded amalgams, there is a dearth of clinical studies to substantiate this in practice. The purpose of this study was to investigate the performance and longevity of bonded and non-bonded amalgam restorations in a general dental practice.

\section{METHOD}

This is a retrospective cohort study of amalgam restorations placed by the author in his general dental practice. The author, having qualified in 1983 in London, has been in general practice since 1985 . The practice, a mixed general dental practice situated in Brierley Hill in the West Midlands, has a clinical computer system that records all clinical records of the patients, EXACT Professional ${ }^{\mathrm{TM}}$ V10 (Software of Excellence International Ltd, Kent, UK).

For most of the author's working life in general practice, patients have been treated predominantly under NHS regulations. In 2003, the author expanded the amount of work carried out under private contract and embarked on an extensive programme of CPD in restorative dentistry. Part of the course included study and tuition of amalgam restorations, which included the theory and practice of a bonded amalgam technique. The methodology learned from the course was introduced into the author's practice in early 2004.

\section{The control group}

The control group consisted of amalgam restorations placed under NHS regulations. Cavities were prepared with a high speed air-rotor handpiece ( $\mathrm{W}_{\mathrm{C}} \mathrm{H}^{\mathrm{Tм}}$, Burmoos, Austria) with diamond or tungsten carbide burs under water irrigation. Caries removal was with round steel burs of variable size depending on the cavity size, at below 40,000 rpm and without irrigation. Isolation was with cotton wool rolls. Following preparation, deep cavities 
were lined where indicated with a calcium hydroxide lining material (Dycal ${ }^{\text {тм}}$, Kerr Corp, CA, USA). Where cusps were missing, additional retention may have been gained by using threaded dentine pins (Stabilok ${ }^{\mathrm{TM}}$, Fairfax Dental, FL, USA).

A Siqveland ${ }^{\mathrm{TM}}$ (DENTSPLY, Surrey, UK) matrix band was used to retain class II cavity walls and the cavity washed and dried. A wedge may have been used, where necessary, although no details were entered in the clinical records to record whether wedges had been used or not. The precise make and composition of the amalgam alloy in use at that time is not known, although it met the required specification for alloys used in the NHS. Following mixing and placement in the cavity, it was condensed by hand using a plugger. After slightly overfilling the cavity, gross carving was carried out and the surface was burnished. The matrix band, if used, was then removed and final finishing carried out with a carver and a probe. The occlusion was checked for intercuspal accommodation and adjusted if necessary.

\section{The test group}

The test group consisted of bonded amalgam restorations placed under private contract. For class II cavities the Automatrix ${ }^{\mathrm{TM}}$ (DENTSPLY, Surrey, UK) matrix band system was used, supported by wedges (Flexiwedge, BISCO, IL, USA) to ensure tight adaptation at the proximal margins. Before use the matrix bands were lubricated with the wax provided by the manufacturer for the purpose. Isolation was with cotton wool rolls. Following washing and drying of the cavity, 37\% phosphoric acid gel was applied to the cavity surface for 15 seconds. It was then washed away and the cavity air dried. Tubulicid ${ }^{\mathrm{TM}}$ (Dental Therapeutics, Stockholm, Sweden) was then applied to the cavity surface for 15 seconds and blot dried. Three applications of ONE-STEP ${ }^{\mathrm{TM}}$ (BISCO, IL, USA) resin were then applied to the cavity, blow dried gently for 5 seconds then light cured for 20 seconds. While curing, a measure of Resinomer ${ }^{\mathrm{TM}}$ (BISCO, IL, USA) was mixed and then applied to the cavity in a thin layer. This was then dried with a 3-in-1 syringe to distribute a thin coating uniformly and prevent pooling. Tytin $^{\mathrm{TM}}$ (Kerr Corp, CA, USA), a spherical amalgam alloy, with high copper content (13\%) was mixed and loaded into the cavity and condensed with a hand plugger before the lining had fully set.

The overfilled cavity was then burnished, and primary carving carried out with a Frahm's carver. The matrix band would then be removed and carving continued with the Frahm's and Hollenbach carvers. Following occlusal adjustment, the restoration would be finished with a pointed burnisher.

In both cases the treatment protocols remained consistent throughout the periods assessed in the study.

\section{Inclusion criteria}

To be eligible for the study, the following inclusion criteria were set:

- Patients must be 18 years of age, or over

- Patients should be regular attendees of the practice (that is, at least once annually)

- The restorations must have been provided by the operator using his normal protocol as described above

- Following restoration, the patient should have re-attended at least once

- All restorations should be intended as permanent (that is, not intended as a core for a crown within the same course of treatment)

- If a replacement for a previous failed restoration, the restoration should be a complete replacement (not a partly replaced 'repaired' restoration).

When assessing the survival, or otherwise, of restorations the following definitions were used:

\section{Censored data}

In the following cases, the restoration had survived up until a known point in time, and the data was regarded as censored:

- If the restoration was still intact with no follow up treatment indicated or prescribed, the restoration was still surviving and the date of the last visit with a dentist was recorded

- If the tooth had been extracted, crowned or root treated, or had required other intervention not related to the original restoration, and the restoration had not failed, then the restoration had survived up until the point of further intervention. The date of the intervention was recorded
- If the patient was no longer attending the practice, the last known survival date was recorded, as the date of the last visit with a dentist.

\section{Failure}

The restoration was deemed to have failed in the following circumstances:

- The restoration had fractured, dislodged or demonstrated marginal failure

- The tooth or part of the tooth had fractured, involving the restoration

- There was secondary caries around the restoration

- The restoration was replaced and the reason for replacement was unknown

- If a crown, root treatment or extraction was prescribed as treatment for a failed restoration or fractured tooth, this was recorded as a failure.

Where there was primary caries, fracture unrelated to the restoration or further intervention necessary that left the restoration intact this was disregarded since the survival of the restoration was unrelated to the episode. If the restoration was replaced or included in the new restoration, it was recorded as a failure.

\section{Sensitivity}

The recording of an incidence of sensitivity depended on a subsequent visit by the patient within a 12-month period, in which they indicated that sensitivity had been experienced. This may have been an incidental finding at a pre-arranged appointment for other treatment, or it may have been a specific complaint at an appointment arranged for the purpose. Equally, a patient may conceivably have experienced sensitivity and not reported it. If sensitivity had been experienced before placement of the restoration or sensitivity was unrelated to the restoration then the instance was disregarded.

\section{Selection of groups}

\section{Control group}

To select the control group, an arbitrary time and date was selected, which was at least ten years in the past. This was so that patients could be monitored over a ten-year period. The author's computerised appointment diary for that date was interrogated and patients who had received 
amalgam restorations were eligible for selection for the study.

Details of amalgam restorations placed on that day were entered onto a spreadsheet, Microsoft Excel ${ }^{\mathrm{TM}} 2003$ (Microsoft Corporation, Redmond, WA, USA), and the following details recorded:

- Date of placement

- Patients' computer code

- Tooth notation

- The notation of surfaces restored

- Whether any postoperative sensitivity was recorded within six months after restoration and was not present before restoration

- Whether the restoration was intact, with no further intervention indicated, at time of follow up

- Any further intervention carried out or indicated

- The number of days from placement to intervention or end point observation

- Allocation of failure or censorship

- Reason for the intervention, if known.

Multiple entries for restorations for the same patient were possible where they had been carried out on the same day, or different days at different times. The date of 1 September 1998 was randomly selected as the start date. Once appointments for that date had been exhausted, the 2 September was then selected. Successive days were followed until the sample size exceeded 200 restorations.

\section{Test group}

The test group consisted of bonded amalgam restorations placed under private contract. This type of restoration, placed according to the treatment protocol, was introduced into the practice in early 2004. It was only possible, therefore, to start the selection of patients from that time. The 18 February 2004 was selected as a start date, since the protocol had been introduced before that time and it would allow a clear five years to assess the survival of the restorations for the majority of the samples.

The sample number selected and the process for collating the data were identical for both groups.

\section{Data analysis}

The data from the spreadsheet was exported into Prism ${ }^{\mathrm{TM}}$ (Version 5.0, Graphpad Software Inc., San Diego, CA,

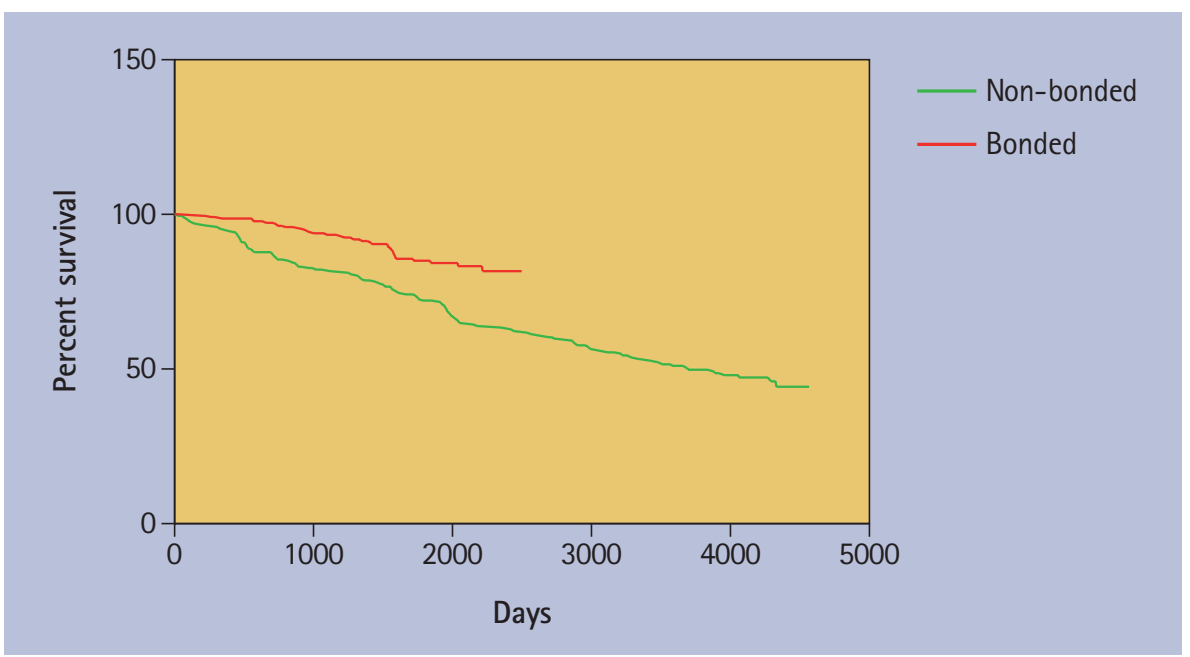

Fig. 1 Survival of non-bonded versus bonded: survival proportions

Table 1 Survival figures of all restorations

\begin{tabular}{|l|l|l|l|l|l|l}
\hline & 1 year & 2 years & 3 years & 4 years & 5 years & 10 years \\
\hline Days & 365 & 730 & 1095 & 1460 & 1825 & 3,650 \\
\hline Non-bonded (\%) & 95.6 & 86.4 & 82.2 & 78.2 & 72.2 & 51.0 \\
\hline Bonded (\%) & 98.7 & 97.3 & 93.5 & 90.4 & 85.0 & N/A
\end{tabular}

\begin{tabular}{|c|c|c|c|c|c|c|}
\hline & 1 year & 2 years & 3 years & 4 years & 5 years & 10 years \\
\hline Days & 365 & 730 & 1095 & 1460 & 1825 & 3,650 \\
\hline Number of non-bonded failures/yr & 10 & 20 & 9 & 8 & 12 & 11 \\
\hline Non-bonded failure rate (\%) & 4.3 & 6.5 & 5.6 & 5.1 & 5.1 & 4.3 \\
\hline Number of bonded failures/yr & 3 & 3 & 8 & 6 & 9 & $N / A$ \\
\hline Bonded failure rate (\%) & 1.3 & 1.3 & 2.0 & 2.2 & 2.5 & $N / A$ \\
\hline
\end{tabular}

Table 3 Sensitivity report

\begin{tabular}{|l|l|l|}
\hline & Non-bonded & Bonded \\
\hline Number reported & 8 & 7 \\
\hline Incidence (\%) & 3.5 & 3.0 \\
\hline Occlusal interference & 4 & 5 \\
\hline Cracked tooth noted at placement & 0 & 1 \\
\hline Pulpitis & 0 & 1 \\
\hline Microleakage & 4 & 0
\end{tabular}

USA) and survival curves generated by the Kaplan-Meier method. A null hypothesis was assumed, which was that there was no difference between the two methods or restoration. The logrank (Mantel-Cox) test and Gehan-Breslaw-Wilcoxon (GBW) test were carried out to test if the assumption of the proportional hazards is true and to calculate $p$ values.

\section{RESULTS}

The compiled data resulted from the collection of sample groups containing 231 non-bonded amalgam restorations and 231 bonded amalgam restorations on 135 NHS and 135 private patients respectively. The non-bonded data retrieval covered the period from 1 September 1998 to 17 May 1999. The bonded data retrieval 
covered the period from 18 February 2004 to 19 December 2006. The retrieval process was completed on 15 March 2011.

\section{Survival}

The overall survival curve generated (Fig. 1, Table 1) indicated that the bonded amalgams had a better survival rate than the non-bonded amalgams and the difference was highly significant ( $\mathrm{p}<0.0001$ ).

For the logrank test, Chi square $\left(\chi^{2}\right)=16.71$ and for the GBW test, $\chi^{2}=17.76$. The hazard ratio was 2.207 (with 95\% CI 1.510 to 3.226), indicating that non-bonded amalgams failed at more than twice the rate that bonded amalgams failed. Nevertheless, the median survival rate of all non-bonded amalgams was more than ten years (3,695 days).

\section{Failure rates}

The number of failed restorations per year was analysed (Table 2). The failure rates were then calculated to indicate the mean failure rate per year after each given time period. This allowed the variability of failure rate to be assessed. These indicated that the peak rate of failure for non-bonded amalgams was during the second year $(6.8 \%)$ although the overall failure rate was $4.9 \%$ (over ten years). The corresponding figure for bonded amalgams was less at 3\% over five years. The number of failures and failure rate of bonded amalgams increased after the second year.

\section{Sensitivity}

Where sensitivity was reported, the cause was further investigated and categorised (Table 3).

In the cases of occlusal interferences, the symptoms resolved following occlusal adjustment. In all the other cases further intervention was necessary, which included root canal treatment, repair or replacement of the restoration or extraction of the tooth.

\section{Failure by type}

A breakdown analysis of restoration type was undertaken. Restorations were classified as follows:

- Class I - single surface, two-surface or three-surface restorations but not including MO or DO involvement

- Class II - MO or D0 restorations including those involving extensions

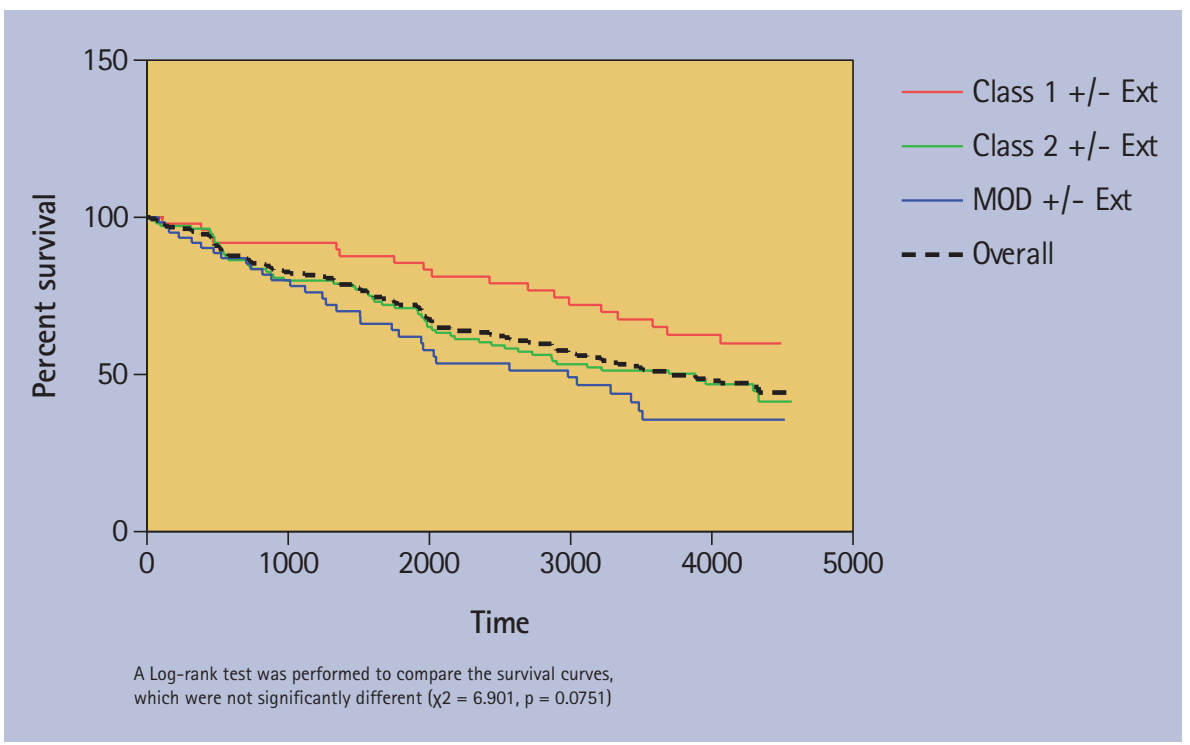

Fig. 2 Survival of non-bonded by type: survival proportions

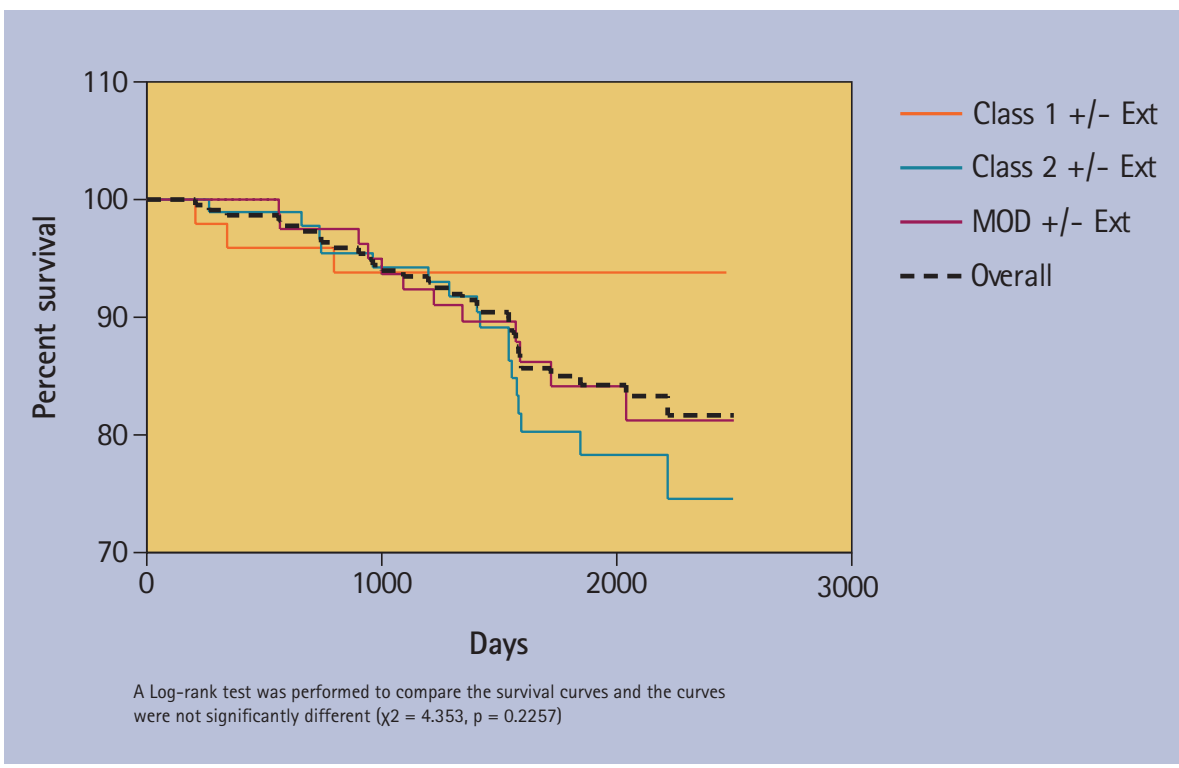

Fig. 3 Survival of bonded by type: survival proportions

and cuspal replacement, but not MOD

- MOD - including those involving

extensions and cuspal replacement.

This enabled the failure of restoration type to be compared, and also the reason for failure. The findings are summarised in Figures 2 and 3 and Tables 4 and 5 .

These results indicate that the survival of the different types of non-bonded restoration were not significantly different when compared with other types of nonbonded restoration; however, they were significantly different when compared to bonded restorations. This was reciprocated with bonded restorations, which were significantly different from non-bonded restorations but not from other types of bonded restorations.

\section{Failure by tooth}

A breakdown analysis by tooth type (that is, molars and premolars) was undertaken to investigate the possibility that tooth location may have been a significant factor. For both non-bonded amalgams and bonded amalgams there was no significant difference between the tooth types within each group $\left(\chi^{2}=2.396, p=0.1216\right.$ for non-bonded and $\chi^{2}=1.107, p=0.2926$ for bonded).

\section{Reasons for failure and other intervention}

The reasons for failure for non-bonded and bonded restorations and other interventions were summarised for comparison in Tables 6 and 7.

In many instances, the reason was unknown because the relevant information 
had not been recorded in the clinical records. Often it was not possible to ascertain the reason for the intervention. For instance, an episode of pulpitis may have originated from a pulpitis secondary to a restoration, or secondarily to periodontal disease. If the cause of the intervention could be ascribed to a restoration failure, it was scored as such; otherwise it was recorded as censored data.

When intervention was necessary, there were generally several treatment options. In all instances, the outcome of an intervention was the result of an informed decision by the patient, which would naturally vary from one patient to another. For instance, in the case of a pulpitis, root canal treatment (RCT) may be one option, but the patient may instead opt for an extraction. Similarly, a restored tooth may have been crowned as part of a structured treatment plan (for example, as a bridge abutment).

\section{DISCUSSION}

The technique for placing bonded amalgams has been described in the literature. Gwinnett et al. described a generic technique $^{42}$ and Staninec and Setcos illustrated a case restored with Panavia 21.41

In this study, the bonded amalgam procedure included the application of Tubulicid after etching. Following etching and drying, the dentine may have been desiccated. Tubulicid contains EDTA and disinfects the dentine; it removes the smear layer and also serves to rehydrate the dentine. The smear layer should be removed to eliminate microbes ${ }^{26}$ and allow penetration of the resin to form a hybrid layer. ${ }^{12}$ Bond strength to dentine has been shown to be unaffected by the application of dentine disinfectants. ${ }^{43}$ ONE-STEP and Resinomer were used as an adhesive system. The author had become familiar with these materials on a postgraduate course and had implemented the technique in his practice. ONE-STEP is a Bis-phenyl DMA/ HEMA resin, and Resinomer if a 57\% glass filled composite resin containing diarylsulphone dimethacrylate (DSDM), which chemically adheres to metal. This system is specifically marketed as an amalgam bonding adhesive by the manufacturers, BISCO, and has been investigated in studies with favourable results, especially when used with Tytin amalgam. ${ }^{18,24}$

\begin{tabular}{|c|c|c|c|c|c|}
\hline & & $\begin{array}{l}\text { Class I } \pm \\
\text { buccal or } \\
\text { lingual } \\
\text { extensions }\end{array}$ & $\begin{array}{l}\text { Class II } \pm \text { I } \\
\text { extensions and } \\
\text { cusp replacement }\end{array}$ & $\begin{array}{l}\text { MOD } \pm \\
\text { extensions } \\
\text { or cusp } \\
\text { replacement }\end{array}$ & $\begin{array}{l}\text { Overall } \\
\text { total }\end{array}$ \\
\hline $\begin{array}{l}\text { Total number of } \\
\text { subjects in study }\end{array}$ & & 51 & 114 & 66 & 231 \\
\hline Number of failures & & 18 & 57 & 32 & 107 \\
\hline Survival at 5 years (\%) & & 85.6 & 71.2 & 62.1 & 72.2 \\
\hline Survival at 10 years (\%) & & 65.2 & 51.3 & 35.7 & 51.0 \\
\hline \multirow[t]{4}{*}{ Reason for failure } & Caries & 2 & 4 & 4 & 10 \\
\hline & $\begin{array}{l}\text { Fractured } \\
\text { tooth }\end{array}$ & 1 & 8 & 3 & 12 \\
\hline & $\begin{array}{l}\text { Fractured } \\
\text { restoration }\end{array}$ & 3 & 5 & 2 & 10 \\
\hline & Unknown & 12 & 40 & 23 & 75 \\
\hline \multirow[t]{3}{*}{ Other intervention } & $\mathrm{RCT}$ & 2 & 4 & 6 & 12 \\
\hline & Crowned & 1 & 3 & 12 & 16 \\
\hline & Extracted & 3 & 6 & 5 & 14 \\
\hline
\end{tabular}

Table 5 Failures of bonded amalgams

\begin{tabular}{|c|c|c|c|c|c|}
\hline & & $\begin{array}{l}\text { Class } 1 \pm \\
\text { buccal or } \\
\text { lingual } \\
\text { extensions }\end{array}$ & $\begin{array}{l}\text { Class II } \pm \text { I } \\
\text { extensions and } \\
\text { cusp replacement }\end{array}$ & $\begin{array}{l}\text { MOD } \pm \\
\text { extensions } \\
\text { or cusp } \\
\text { replacement }\end{array}$ & $\begin{array}{l}\text { Overall } \\
\text { total }\end{array}$ \\
\hline $\begin{array}{l}\text { Total number of } \\
\text { subjects in study }\end{array}$ & & 49 & 95 & 87 & 231 \\
\hline Number of failures & & 3 & 17 & 12 & 32 \\
\hline Survival at 5 years $(\%)$ & & 93.8 & 80.3 & 84.2 & 85.0 \\
\hline \multirow[t]{4}{*}{ Reason for failure } & Caries & 3 & 5 & 6 & 14 \\
\hline & $\begin{array}{l}\text { Fractured } \\
\text { tooth }\end{array}$ & 0 & 4 & 2 & 6 \\
\hline & $\begin{array}{l}\text { Fractured } \\
\text { restoration }\end{array}$ & 0 & 4 & 2 & 6 \\
\hline & Unknown & 0 & 4 & 2 & 6 \\
\hline \multirow[t]{3}{*}{ Other intervention } & $\mathrm{RCT}$ & 0 & 1 & 2 & 3 \\
\hline & Crowned & 0 & 4 & 8 & 12 \\
\hline & Extracted & 4 & 7 & 7 & 18 \\
\hline
\end{tabular}

Several studies have reported on the longevity of amalgam restorations. Hickel and Manhart conducted a survey on the longevity of restorations of posterior teeth. ${ }^{44}$ They analysed clinical studies of non-bonded amalgam restorations and concluded that the annual failure rate of amalgam restorations was between $0 \%$ and $7 \%$ per year, with a median failure rate of 3.3\%. Secondary caries, fracture of filling or tooth and marginal ditching were the main reasons for failure. High copper amalgams performed better than conventional alloys and larger restorations deteriorated more rapidly than smaller restorations.

In England and Wales, NHS dental care was provided in the general dental services (GDS) until 2006. Amalgam restorations placed in the GDS were recorded on the GDS database in Eastbourne, Sussex. Lucarotti et al. interrogated the GDS database to consider factors associated with various restorations. ${ }^{45}$ This was drawn from a very large database $(503,965$ restorations) and serves as a yardstick for 


\begin{tabular}{|c|c|c|c|c|}
\hline \multirow[t]{2}{*}{ Reason for failure } & \multicolumn{2}{|c|}{ Non-bonded } & \multicolumn{2}{|l|}{ Bonded } \\
\hline & $\begin{array}{l}\text { No. of } \\
\text { failures }\end{array}$ & $\begin{array}{l}\text { Percentage } \\
\text { of failures }\end{array}$ & $\begin{array}{l}\text { No. of } \\
\text { failures }\end{array}$ & $\begin{array}{l}\text { Percentage } \\
\text { of failures }\end{array}$ \\
\hline Caries & 10 & 9.4 & 14 & 43.8 \\
\hline Fractured tooth & 12 & 11.3 & 6 & 18.8 \\
\hline Fractured restoration & 10 & 9.4 & 6 & 18.8 \\
\hline Unknown & 75 & 70.1 & 6 & 18.8 \\
\hline Total & 106 & 100 & 32 & 100 \\
\hline
\end{tabular}

\begin{tabular}{|c|c|c|c|c|}
\hline \multirow[t]{2}{*}{ Other intervention } & \multicolumn{2}{|l|}{ Non-bonded } & \multicolumn{2}{|l|}{ Bonded } \\
\hline & No. in sample & $\begin{array}{l}\text { Percentage of } \\
\text { sample }\end{array}$ & No. in sample & $\begin{array}{l}\text { Percentage of } \\
\text { sample }\end{array}$ \\
\hline RCT & 12 & 5.2 & 3 & 1.3 \\
\hline Crowned & 16 & 6.9 & 12 & 5.2 \\
\hline Extracted & 14 & 6.1 & 18 & 7.8 \\
\hline Total & 231 & 100 & 231 & 100 \\
\hline
\end{tabular}

Table 8 Survival rates (\%)

\begin{tabular}{|l|l|l|l|l|}
\hline & \multicolumn{2}{|l|}{ GDS NHS } & \multicolumn{2}{l}{ Study non-bonded } \\
\cline { 2 - 5 } & 5 years & 10 years & 5 years & 10 years \\
\hline Class I with extensions & 70.4 & 56.4 & 85.6 & 65.2 \\
\hline Class II with ext (not MOD) & 65 & 49 & 71.2 & 51.3 \\
\hline MOD with extensions & 60 & 43 & 62.1 & 35.7
\end{tabular}

comparison. A summary of their findings is presented along with comparative results from the present study in Table 8.

In their analysis, they found that the overall survival rate of all amalgam restorations placed in the GDS was 50.1\% over ten years. The annual failure rate of amalgam restorations ranged from $4.2 \%$ to $5.7 \%$ for single surface and MOD restorations respectively. The results of the non-bonded amalgam restorations in the current study compared favourably with the GDS figures, with overall survival of 51\% over the same period. Survival of all categories of restoration type was better in the present study than the GDS figures, except for MOD restoration survival, which was less in the current study at $36 \%$, but the differences between types was not statistically significant $\left(\chi^{2}=6.901, p=0.0751\right)$.

Using the non-bonded amalgam restorations as a benchmark allows a meaningful comparison with bonded restorations. Bonded restorations demonstrated better survival than non-bonded restorations and the difference was significant ( $p<0.0001$ ). Other than the bonded technique there were other variables. The same operator performed all the restorations. The patient selection was from the same pool and, indeed, the same operator originally treated most of the patients treated with bonded restorations as NHS patients. Tooth preparation was similar, with the exception that retention pins may have been used for non-bonded restorations, but not at all for bonded restorations and bonded preparations could be more conservative in their design. On the other hand, the majority of restorations were placed as replacements for existing restorations and so there was little scope to be conservative in many cases. The method of isolation was the same in both groups, cotton wool rolls, although use of rubber dam has been advocated for bonded restoration placement. ${ }^{41,42}$ Other clinical variables between the two groups, apart from the use of the bonding technique, were the type of amalgam used and the matrix system. Wedges were used, where appropriate, for bonded restorations. Wedges may also have been used for some non-bonded restorations. However, the clinical records did not record this information and so any assumption about the use of wedges for non-bonded restorations is unreliable.

Non-bonded restorations were placed under NHS regulations, whereas the bonded restorations were placed under private contract. More appointment time was allocated to the provision of bonded restorations than non-bonded restorations. At the time of placement of the non-bonded restorations, the operator had been in general practice for over 15 years, predominantly in the NHS. The bonded amalgam restorations were placed approximately five years later. During this period, the operator had attended courses in CPD and gained an additional five years clinical experience. It is possible that these factors may have influenced the placement of the restorations and subsequently the longevity and performance of the restorations.

In order to limit the possible introduction of bias the author's dental nurse carried out the data retrieval. She had been given instructions on the selection criteria, sample selection and data collection and she then collated the information on to the spreadsheet. The data was then transferred into the data analysis software for the survival analysis by the author, who was then working with coded data.

As bonded amalgam data was only available for five years, it is not possible to make direct comparison with both types of restoration for longer than this time period within this study. However, the non-bonded amalgam restorations survival can be compared with national GDS figures over a ten-year period, for which data is available. ${ }^{45}$

The rate of failure was also different between the two groups. The non-bonded amalgams survived better in the first year (4.3\% failure), then performed worse in the second year (6.5\% failure), before gradually improving each year to settle at 4.3\% per year after ten years. Bonded amalgams performed better in the first two years 
(1.3\% per year) and then the failure rate gradually increased up to $2.5 \%$ after five years. Bonsor et al. ${ }^{4}$ also noticed this pattern. In his study, a decline in survival was noted at around 1,000 days. ${ }^{4}$ This may be a phenomenon whereby deterioration of the adhesive, after a certain time has elapsed, may cause an increased incidence of failure. This may merit further investigation in a long-term prospective study, preferably over ten years.

The results for sensitivity are unreliable, since the recording of sensitivity was incidental. However, the overall sensitivity was very similar for both groups, supporting the findings of other studies that there is no difference in sensitivity between bonded and non-bonded restorations. ${ }^{34,35,37}$ Upon further analysis, it appears that the cause of sensitivity for the non-bonded amalgams may have included microleakage, whereas there was no evidence of this in the bonded amalgam group. The one instance of pulpitis had demonstrated symptoms of pulpitis before the restoration was placed and the cracked tooth was noted to have a crack line extending across the floor of the cavity at the time of placement. All other cases of sensitivity were due to occlusal interferences, which resolved following adjustment, and therefore were probably not due to microleakage.

The reasons for failure were analysed for both groups. In the non-bonded group, the reason was unknown in $70 \%$ of cases. It was noticeable that the quality of the clinical notes for the non-bonded group was not as comprehensive as for the bonded group and the non-bonded figures should therefore be interpreted with caution. The figures for bonded restorations were more informative, although in 18\% of cases the precise cause of failure was not clear. However, the figures indicated that caries was the most common cause of failure. Secondary caries has been suggested as the most common cause of failure of amalgam restorations with an incidence of up to $50 \% 0^{46-48}$ and this finding is supported in the present study. It is not clear whether the incidence in this study $(43.8 \%)$ is a result of primary or secondary caries. It is possible that an incidence of caries within a tooth may have resulted in replacement of the restoration, and therefore been scored as a failure, when the cavity may have been in a different part of the tooth and unrelated to the restoration.

Similarly, when analysing other interventions there was a lack of relevant information in the clinical notes to enable full details to be extracted. This is a common problem with retrospective studies and makes interpretation of the results difficult. It is possible that the reduced number or bonded amalgams requiring root canal therapy was because there was a reduced incidence of microleakage leading to pulp death. Alternatively, it may be that the patient in question may have opted to have the troublesome tooth extracted instead.

Conventionally, amalgam restorations placed under NHS regulations are nonbonded, and practitioners treating patient's in general dental practice do so under certain financial and time constraints. The placement of bonded amalgam restorations incurs additional clinical time and extra cost. As clinicians, we want to provide the best care for our patients and both clinician and patient will want to feel confident that the extra time and financial outlay incurred in placing bonded restorations are well spent and represent value for money in terms of performance and longevity. The results of this study indicate that there is a significant difference between a non-bonded amalgam restoration and a bonded amalgam restoration, although the outcomes found in this study relate to a single operator and may not necessarily be comparable with other operators. However, these findings present the clinician with an ethical dilemma. Should he provide a non-bonded amalgam restoration for his patient under NHS regulations, knowing that this may not be the best restoration he can provide? Should he provide a bonded amalgam privately? Or should he provide a bonded amalgam on the NHS? This must be a decision made after consideration of all the circumstances and with the involvement of the patient, from whom informed consent can be granted only when they have been provided with all the facts, and, after all, in whose tooth the restoration will be placed.

\section{CONCLUSION}

In this retrospective cohort clinical study, 231 non-bonded amalgam restorations were compared with 231 bonded amalgam restorations and compared for survival rates and clinical performance. Within the limitations of the study, the following conclusions can be drawn:

1. Bonded amalgam restorations provided significantly greater longevity than non-bonded amalgam restorations over a five-year period

2. The comparison of postoperative sensitivity rates between the two methods of restoration was inconclusive

3. Bonded amalgam restorations may offer a significant benefit compared to non-bonded amalgam restorations in terms of survival and re-intervention, but this is at the expense of additional clinical time and increased cost.

Grateful thanks are extended to Stacey Partridge, dental nurse, whose conscientious diligence and attention to detail greatly assisted with the retrieval of the data.

1. Berry T G, Summitt J B, Chung A K, Osborne J W. Amalgam at the new millennium. J Am Dent Assoc 1998; 129: 1547-1556.

2. Anderson M H, McCoy R B. Dental amalgam. The state of the art and science. Dent Clin North Am 1993; 37: 419-431.

3. Eley $B$ M. The future of dental amalgam: a review of the literature. Part 1: dental amalgam structure and corrosion. Br Dent J 1997; 182: 247-249.

4. Bonsor S J, Chadwick R G. Longevity of conventional and bonded (sealed) amalgam restorations in a private general dental practice. Br Dent J 2009; 206: E3.

5. Osborne J W, Norman R D, Gale E N. A 14-year clinical assessment of 12 amalgam alloys. Quintessence Int 1991; 22: 857-864.

6. Burke F J. From extension for prevention to prevention of extension: (minimal intervention dentistry). Dent Update 2003; 30: 492-498, 500, 502.

7. Tyas M J, Anusavice K J, Frencken J E, Mount G J. Minimal intervention dentistry - a review. FDI Commission Project 1-97. Int Dent J 2000; 50: 1-12.

8. Peters M C, McLean M E. Minimally invasive operative care. I. Minimal intervention and concepts for minimally invasive cavity preparations. J Adhes Dent 2001; 3: 7-16.

9. Setcos J C, Staninec M, Wilson N H. The development of resin-bonding for amalgam restorations. Br Dent J 1999: 186: 328-332.

10. Buonocore M G. A simple method of increasing the adhesion of acrylic filling materials to ename surfaces. J Dent Res 1955; 34: 849-853.

11. Fusayama T, Nakamura M, Kurosaki N, Iwaku M. Non-pressure adhesion of a new adhesive restorative resin. J Dent Res 1979; 58: 1364-1370.

12. Nakabayashi N, Nakamura M, Yasuda N. Hybrid layer as a dentin-bonding mechanism. J Esthet Dent 1991; 3: 133-138.

13. Setcos J C. Staninec M, Wilson N H. Bonding of amalgam restorations: existing knowledge and future prospects. Oper Dent 2000; 25: 121-129.

14. Varga J, Matsumura $H$, Masuhara E. Bonding of amalgam filling to tooth cavity with adhesive resin. Dent Mater J 1986; 5: 158-164.

15. Shimizu A, Ui T, Kawakami M. Bond strength between amalgam and tooth hard tissues with application of fluoride, glass ionomer cement and adhesive resin cement in various combinations. Dent Mater J 1986; 5: 225-232.

16. Staninec $M$, Holt $M$. Bonding of amalgam to tooth structure: tensile adhesion and microleakage tests. J Prosthet Dent 1988; 59: 397-402.

17. Ramos J C, Perdigão J. Bond strengths and SEM morphology of dentin-amalgam adhesives. Am J 
Dent 1997; 10: 152-158.

18. Diefenderfer K E, Reinhardt J W. Shear bond strengths of 10 adhesive resin/amalgam combinations. Oper Dent 1997; 22: 50-56.

19. Staninec M. Retention of amalgam restorations: undercuts versus bonding. Quintessence Int 1989 20: 347-351.

20. Larson T D, Douglas W H, Geistfeld R E. Effect of prepared cavities on the strength of teeth. Oper Dent 1981; 6: 2-5.

21. Boyer D B, Roth L. Fracture resistance of teeth with bonded amalgams. Am J Dent 1994; 7: 91-94.

22. el-Badrawy W A. Cuspal deflection of maxillary premolars restored with bonded amalgam. Oper Dent 1999; 24: 337-343.

23. Oliveira J P, Cochran M A, Moore B K. Influence of bonded amalgam restorations on the fracture strength of teeth. Oper Dent 1996; 21: 110-115.

24. Pilo R, Brosh T, Chweidan H. Cusp reinforcement by bonding of amalgam restorations. J Dent 1998; 26: 467-472.

25. Eakle W S, Staninec M, Lacy A M. Effect of bonded amalgam on the fracture resistance of teeth. J Prosthet Dent 1992; 68: 257-260.

26. Brännström M. The cause of postrestorative sensitivity and its prevention. J Endod 1986; 12: 475-481.

27. Cox C F, Keall C L, Keall H J, Ostro E, Bergenholtz G. Biocompatibility of surface-sealed dental materials against exposed pulps. J Prosthet Dent 1987; 57: 1-8.

28. Kohalmi T, Gorzó I, Mari A, Boda K, Nagy K. [In vitro comparison of marginal adaptation of different filling materials. II. Effect of the site and method of preparation on the marginal adaptation]. Fogorv $S z$ 1999: 92: 111-121.

29. Meiers J C, Turner E W. Microleakage of dentin/ amalgam alloy bonding agents: results after 1 year. Oper Dent 1998; 23: 30-35.

30. Torii Y, Staninec M, Kawakami M, Imazato S, Torii $M$, Tsuchitani Y. Inhibition in vitro of caries around amalgam restorations by bonding amalgam to tooth structure. Oper Dent 1989; 14: 142-148.

31. Saiku J M, St Germain H A, Jr, Meiers J C. Microleakage of a dental amalgam alloy bonding agent. Oper Dent 1993; 18: 172-178.

32. Ruzicková T, Staninec M, Marshall G W, Hutton J E. Bond strengths of the adhesive resin-amalgam interface. Am J Dent 1997; 10: 192-194.

33. Fedorowicz Z, Nasser M, Wilson N. Adhesively bonded versus non-bonded amalgam restorations for dental caries. Cochrane Database Syst Rev 2009: CD007517.

34. Setcos J C, Staninec M, Wilson N H. A two-year randomized, controlled clinical evaluation of bonded amalgam restorations. J Adhes Dent 1999; 1:323-331

35. Browning W D, Johnson W W, Gregory P N. Clinical performance of bonded amalgam restorations at 42 months. J Am Dent Assoc 2000; 131: 607-611.

36. Mach Z, Regent J, Staninec M, Mrklas L, Setcos J C The integrity of bonded amalgam restorations: a clinical evaluation after five years. J Am Dent Assoc 2002; 133: 460-467.

37. Mahler D B, Engle J H. Clinical evaluation of amalgam bonding in Class I and II restorations. J Am Dent Assoc 2000; 131: 43-49.

38. Smales R J, Wetherell J D. Review of bonded amalgam restorations, and assessment in a general practice over five years. Oper Dent 2000; 25: 374-381.

39. Summitt $」 B$, Burgess $」 O$, Berry $T G$, Robbins $J W$, Osborne J W, Haveman C W. Six-year clinical evaluation of bonded and pin-retained complex amalgam restorations. Oper Dent 2004; 29: 261-268.

40. Staninec M, Artiga N, Gansky S A, Marshall G W, Eakle S. Bonded amalgam sealants and adhesive resin sealants: five-year clinical results. Quintessence Int 2004; 35: 351-357.

41. Staninec M, Setcos J C. Bonded amalgam restorations: current research and clinical procedure. Dent Update 2003: 30: 430-434, 436.

42. Gwinnett A J, Baratieri L N, Monteiro S, Jr, Ritter A V. Adhesive restorations with amalgam: guidelines for the clinician. Quintessence Int 1994; 25: 687-695

43. Gwinnett A J. Effect of cavity disinfection on bond strength to dentin. J Esthet Dent 1992; 4: 11-13.

44. Hickel R, Manhart J. Longevity of restorations in posterior teeth and reasons for failure. J Adhes Dent 2001; 3: 45-64.

45. Lucarotti PS, Holder R L, Burke F J. Outcome of direct restorations placed within the general dental services in England and Wales (Part 1): variation by type of restoration and re-intervention. J Dent 2005; 33: 805-815.

46. Mjör I A. The reasons for replacement and the age of failed restorations in general dental practice. Acta Odontol Scand 1997; 55: 58-63.

47. Qvist J, Qvist V, Mjör I A. Placement and longevity of amalgam restorations in Denmark. Acta Odontol Scand 1990; 48: 297-303.

48. Burke F J, Cheung S W, Mjor I A, Wilson N H. Restoration longevity and analysis of reasons for the placement and replacement of restorations provided by vocational dental practitioners and their trainers in the United Kingdom. Quintessence Int 1999; 30: 234-242. 